\title{
PLASTICITY OF VASCULAR PROGENITOR CELLS: IMPLICATIONS IN PULMONARY VASCULAR REMODELLING IN COPD
}

\author{
M. Díez, V.I. Peinado, E. Ferrer, J. Ramírez, J. Roca, R. Rodriguez-Roisin and J.A. Barberà \\ Depts of Pulmonary Medicine and Pathology, Idibaps-Hospital Clinic, University of Barcelona, Barcelona, Spain
}

WINNING ABSTRACT: Vascular progenitor cells (VPC) have shown in vitro and in vivo their ability to differentiate into endothelial cells (EC). Some evidence suggests that the plasticity of these cells to differentiate into other cell types might contribute not only to angiogenesis but also to perpetuate vascular lesions. Studies done in pulmonary arteries (PA) of patients with COPD have demonstrated the presence of VPC infiltrating the intima. Since intimal thickening is mainly constituted by smooth muscle cells (SMC), we asked whether VPC could play a role in wall thickening. Accordingly, the objective was to evaluate in vitro the plasticity of VPC to differentiate into SMC and EC of human PA. G-CSF-mobilized peripheral blood CD133+ cells from a commercial primary line were expanded and labelled with acetylated-LDL-Dil for tracking cell purposes. Then, cells were co-cultured with commercial primary lines of human PA EC or SMC $(n=3)$. As control, CD133+ cells were cultured alone, with minimal medium with or without VEGF $\left(50 \mathrm{ng} \cdot \mathrm{ml}^{-1}\right)$. After 6 and 12 days of growth, the phenotype of cultures was characterized by immunofluorescence with: lectin, $\alpha$-actin and CD31. Cells were also evaluated morphologically. After 6 days, VPC acquired the morphology and the phenotype of the cells with which they were co-cultured, EC (lectin+, CD31+, $\alpha$-actin-) or SMC ( $\alpha$-actin+, lectin-, CD31-). VPC cultured 12 days alone or with VEGF did not acquire typical morphology and markers of mature EC or SMC of PA. We conclude that VPC have the potential to differentiate in vitro into SMC, and that this plasticity could contribute to perpetuate pulmonary vascular remodelling in COPD.

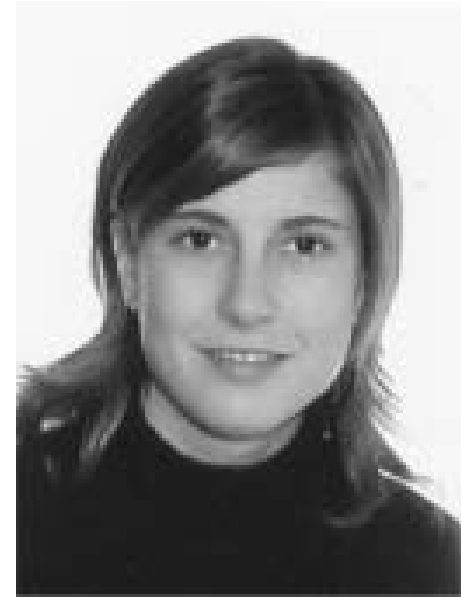

Marta Díez

Physiological Mechanisms of Respiratory Diseases Laboratory, IDIBAPS, Hospital Clinic de Barcelona, Barcelona, Spain

\section{MY JOB AND THE UNIT IN WHICH I WORK}

I work in the research laboratory of the Pneumology Service in the Institut d'Investigacions August Pi i Sunyer (IDIBAPS) at the Hospital Clinic of Barcelona (Barcelona, Spain). IDIBAPS is outstanding in clinical and experimental research. The Hospital Clinic of Barcelona, which is part of the IDIBAPS, is one of the top 10 hospitals within the European Union in terms of scientific production, and it has the highest scientific production of any hospital in Spain.

The respiratory group has focused its research on the clinical and basic aspects of pulmonary circulation and muscle function in chronic obstructive pulmonary disease (COPD). My job in the group consists of carrying out all basic procedures to assess the number of circulating progenitors in patients with COPD, and to investigate whether these measurements correlate with vascular function impairment. More recently, we have extended our objectives to identify the stem cells that take part in the angiogenesis and the repair process of pulmonary arteries and to identify the potential mechanisms of cell differentiation. These studies constitute my present PhD in the field of cellular and molecular biology in pulmonary vascular remodelling in COPD.

\section{MY WINNING ABSTRACT AS PART OF MY RESEARCH}

Recent studies have shown that bone marrow cells may have the potential to give rise to vascular progenitor cells, which have the capacity to mobilise, migrate to sites of vascular injury and differentiate into endothelial or smooth muscle cells, thereby contributing to vascular repair. This process has not yet been fully demonstrated in human pulmonary circulation.

In a previous study [1], we identified bone marrow-derived stem cells in the intima of pulmonary arteries of patients with COPD. Their presence was associated with the enlargement of the pulmonary artery wall, thus suggesting the potential participation of progenitor cells in the remodelling process. To gain further insight into the role of these cells in tissue repair and lesion formation, I conducted new research aimed at investigating the plasticity of circulating human progenitor cells (CD133+) differentiating in vitro into pulmonary artery smooth muscle and/or endothelial cells in order to determine whether they can be a potential source of proliferating cells in hyperplasic artery walls. 


\section{MY RESEARCH AS PART OF MY WORKING GROUP/ RESEARCH TEAM}

The work that I have started is the continuation of ongoing research that was initiated several years ago in the Pulmonary Circulation and Respiratory Diseases group in the Hospital Clinic, Barcelona, Spain. This group, led by Dr Barberà, has recognised experience in the field of COPD. The group has focused its activity on the cellular and molecular mechanisms of pulmonary vascular abnormalities associated with COPD. The major achievements of the group have been as follows: 1) demonstration that changes in pulmonary arteries occur at early stages $[2,3]$; 2) characterisation of the cellular and molecular changes in pulmonary arteries [4]; 3) implication of cigarette smoking in the pathogenesis of pulmonary vascular abnormalities through an inflammatory mechanism [5]; 4) impact of endothelial dysfunction on the vascular response to hypoxia and gas exchange regulation [6]; 5) characterisation of mediators that contribute to vascular remodelling [7]; and 6) identification of vascular progenitor cells in the intima of pulmonary arteries from patients with COPD [1]. The group takes part in the European Union-funded Integrated Project PULMOTENSION.

\section{THE IMPACT OF MY WORK ON CLINICAL OR RESEARCH PRACTICE}

The identification of stem cells that take part in the angiogenesis and repair process of pulmonary arteries in patients with COPD will suggest a scientific base that allows us, eventually, to design therapeutic strategies designed to control these structural changes, thereby establishing a novelty in the treatment of pulmonary circulation alterations associated with COPD. Likewise, exploration of the mechanisms that underlie the linkage between CD133+ differentiation and intimal thickening in injured arteries may be important in understanding vascular repair and perhaps lead to novel approaches for prevention of remodelling.

\section{REFERENCES}

1 Peinado VI, Ramírez, Roca J, et al. Identification of vascular progenitor cells in pulmonary arteries of patients with COPD. Am J Respir Cell Mol Biol 2006; 34: 257-263.

2 Peinado VI, Barberà JA, Ramírez J, et al. Endothelial dysfunction in pulmonary arteries of patients with mild COPD. Am J Physiol 1998; 274: L908-L913.

3 Barberà JA, Peinado VI, Santos S, et al. Reduced expression of endothelial nitric oxide synthase in pulmonary arteries of smokers. Am J Respir Crit Care Med 2001; 164: 709-713.

4 Santos S, Peinado VI, Ramirez J, et al. Characterization of pulmonary vascular remodelling in smokers and patients with mild COPD. Eur Respir J 2002; 19: 632-638.

5 Peinado VI, Barberà JA, Abate $\mathrm{P}$, et al. Inflammatory reaction in pulmonary muscular arteries of patients with mild chronic obstructive pulmonary disease. Am J Respir Crit Care Med 1999; 159: 1605-1611.

6 Peinado VI, Santos S, Ramírez J, et al. Response to hypoxia of pulmonary arteries in chronic obstructive pulmonary disease. Eur Respir J 2002; 20: 332-338.

7 Santos S, Peinado VI, Ramirez J, et al. Enhanced expression of vascular endothelial growth factor in pulmonary arteries or smokers and patients with moderate chronic obstructive pulmonary disease. Am J Respir Crit Care Med 2003; 167: 1250-1256. 